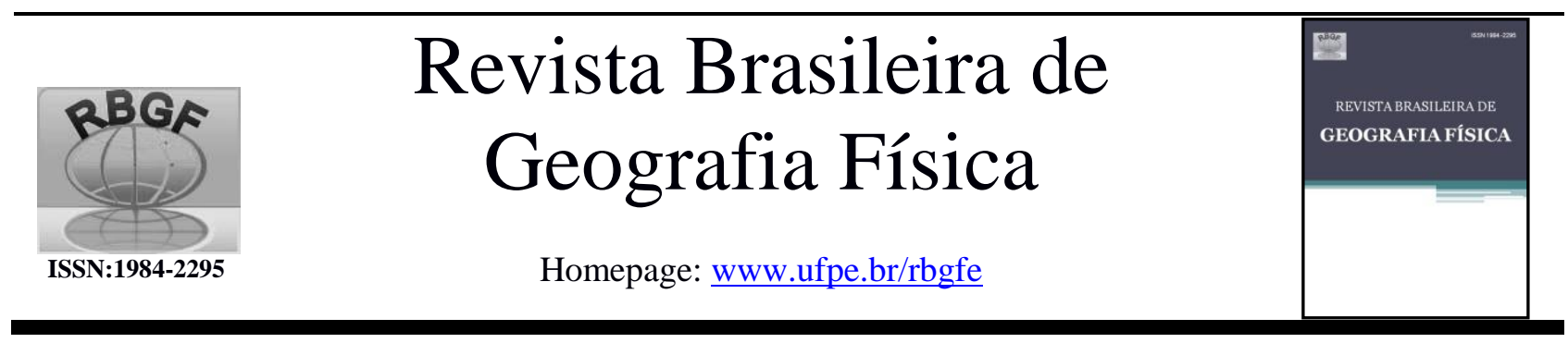

\title{
Atenuação da Energia das Ondas sobre uma Rampa que atua como Estrutura de Proteção Costeira na Plataforma Sul do Brasil
}

\author{
Thaísa Beloti Trombetta ${ }^{1}$, Phelype Haron Oleinik ${ }^{2}$, Bruno Vasconcellos Lopes ${ }^{3}$, Ricardo Cardoso \\ Guimarães ${ }^{4}$, Wiliam Correa Marques ${ }^{5}$, Liércio André Isoldi ${ }^{6}$.
}

\begin{abstract}
${ }^{1}$ Mestranda em Engenharia Oceânica, Universidade Federal do Rio Grande, Campus Carreiros, Rio Grande, Rio Grande do Sul, Brasil, thaisa_bt@ hotmail.com (autor correspondente). ${ }^{2}$ Graduando em Engenharia Civil Costeira e Portuária, Universidade Federal do Rio Grande, Campus Carreiros, Rio Grande, Rio Grande do Sul, Brasil, phe.h.o1 @ gmail.com. ${ }^{3}$ Mestrando em Engenharia Oceânica, Universidade Federal do Rio Grande, Campus Carreiros, Rio Grande, Rio Grande do Sul, Brasil, lopesbruno13@gmail.com. ${ }^{4}$ Graduando em Engenharia Mecânica, Universidade Federal do Rio Grande, Campus Carreiros, Rio Grande, Rio Grande do Sul, Brasil, ricardo_guimaraes@ hotmail.com. ${ }^{5}$ Doutor em Oceanografia Física, Química e Geológica, Professor no Instituto de Matemática, Estatística e Física (IMEF) e nos Programas de PósGraduação: Modelagem Computacional (PPGMC), Oceanografia Física, Química e Geológica (PPGOFQG) e Engenharia Oceânica (PPGEO), Universidade Federal do Rio Grande, Campus Carreiros, Rio Grande, Rio Grande do Sul, Brasil, wilianmarques47@ gmail.com. ${ }^{6}$ Doutor em Engenharia, Professor na Escola de Engenharia (EE) e nos Programas de PósGraduação: Modelagem Computacional (PPGM) e Engenharia Oceânica (PPGEO), Universidade Federal do Rio Grande, Campus Carreiros, Rio Grande, Rio Grande do Sul, Brasil, liercioisoldi@ gmail.com.
\end{abstract}

Artigo recebido em 27/11/2017 e aceito em 01/06/2018

\begin{abstract}
R E S U M O
O estudo da erosão costeira no estado de Santa Catarina aponta para a problemática resultante da ação das ondas com alta intensidade energética sobre a costa. Deste modo, o presente estudo tem por finalidade analisar o comportamento das ondas sobre a costa da região Catarinense e definir a área com maior potencial energético, utilizando ferramentas de modelagem computacional. A partir destes resultados foi proposta a inserção de uma rampa na região de estudo, de modo que atuasse como estrutura de proteção costeira, através da dissipação da energia das ondas. Logo, utilizando dados de reanálise atmosféricos e simulações de ondas forçadas pelo vento ao longo do ano de 2014, foi verificado que a região do Cabo de Santa Marta localizada em Laguna, possui os valores mais elevados de potencial energético das ondas ao compará-la às regiões costeiras adjacentes na costa catarinense. Assim, os resultados desta análise numérica mostraram o comportamento das ondas antes e após a instalação da rampa, resultando em uma atenuação de até $98 \%$ da altura das ondas que se aproximam da costa, e aproximadamente $90 \%$ do potencial energético. Por fim, a instalação da rampa se mostrou uma alternativa válida para a proteção da costa na região do Cabo de Santa Marta, visto que tem capacidade de atenuar os efeitos erosivos causados pelas ondas na área litorânea, sendo então uma sugestão de possíveis alternativas na área da engenharia capazes de reverter a problemática da erosão costeira.

Palavras-Chave: Onda, erosão, TOMAWAC, proteção costeira, zona costeira.
\end{abstract}

\section{A B S T R A C T}

The erosion study over Santa Catarina shore lead to the problem resulting from the action of high intensity energetic waves on the coast. Therefore, the present study aims to analyze the wave action over the Santa Catarina shoreline in addition to characterize the most energetic area using numerical models. From these results it was proposed the insertion of a ramp in the study region, so that it acts as a structure of coastal protection, through the dissipation of the waves energy. Therefore, using atmospheric reanalysis data and wind forced wave simulations throughout 2014, it was verified that the Santa Marta Cape region located in Laguna has the highest values of wave energy potential when compared to the adjacent coastal regions on the Santa Catarina coast. Thus, the numerical analysis results showed the waves behavior before and after the installation of the ramp, resulting in an attenuation of up to $98 \%$ of the waves height approaching the coast, and approximately $90 \%$ of the energy potential. Finally, the installation of the ramp proved to be a valid alternative for the coast protection in the Cabo de Santa Marta region, since it has the capacity to attenuate the erosive effects caused by the waves in the coastal area, being a suggestion of possible alternatives in the area capable of reversing the coastal erosion problems.

Keywords: Wave, erosion, TOMAWAC, coastal protection, coastal zone. 


\section{Introdução}

As mudanças climáticas resultantes do aquecimento global têm sido um fator extremamente preocupante para a sociedade e para o meio ambiente nos últimos anos. Previsões relacionadas aos efeitos das mudanças climáticas globais sugerem o agravamento da situação de risco, pois indicam um aumento da intensidade das tempestades costeiras e também da frequência de eventos repentinos de subida do nível do mar nos próximos anos (Solomon et al., 2007). A elevação do nível médio global do mar relaciona-se com a variabilidade climatológica natural da Terra e com as perturbações induzidas pelas atividades humanas (Dias, 1993). Segundo o AR5 (Fifth Assessment Report), publicado pelo Painel Intergovernamental para as Mudanças Climáticas (IPCC, 2014), os sistemas costeiros experimentarão cada vez mais submersão, inundações e erosão ao longo do século XXI, devido ao aumento do nível do mar. Os índices do IPCC (2014) também demonstraram que no final do século XXI, é muito provável que o nível do mar aumente em mais de $95 \%$ das áreas oceânicas do mundo, sendo que para o período 2081-2100, a elevação provavelmente será nos intervalos de 0,45 a $0,82 \mathrm{~m}$.

A erosão em uma praia se torna problemática quando passa a ser um processo severo e permanente ao longo de toda essa praia ou em trechos dela, ameaçando áreas de interesse ecológico e socioeconômico (Souza et al., 2005). Além disso, as mudanças globais aparentemente têm repercutido no aumento da frequência e intensidade de tempestades e do nível do mar, o que agrava ainda mais este cenário (McGuire et al., 2002). Dessa maneira, o litoral fica exposto a maiores riscos, e milhares de pessoas são atingidas anualmente por inundações.

No Brasil, a maior parte do litoral encontra-se em erosão, tendo um panorama geral da distribuição de áreas de erosão/acreção na costa brasileira sido apresentado por Muehe (2006). Dados relativos à década de 1990 mostravam que, já naquela época, $70 \%$ das praias arenosas do planeta estavam em erosão, $20 \%$ em deposição e apenas $10 \%$ se encontravam em relativa estabilidade (Bird, 1999). Cientistas estimam que cerca de $40 \%$ dos $8.500 \mathrm{~km}$ do litoral brasileiro sofrem um grave processo erosivo (Muehe, 2006).

A ocupação em áreas inadequadas, estimulada pelo desenvolvimento de atividades como turismo, transporte, pesca e indústria, tem desencadeado e/ou acelerado processos erosivos ao longo da costa (Wisner et al., 2004). Neste sentido, à medida que a ocupação da zona costeira vem aumentando, os efeitos erosivos que antes eram ignorados por não causarem prejuízos, passaram a ser vistos como fatores de risco, implicando em questões econômicas e sociais bastante relevantes (Muehe, 2006).

As praias arenosas apresentam uma dinâmica própria em virtude da mobilidade dos sedimentos, transportada pelos efeitos constantes das ondas, correntes litorâneas, marés e ventos, resultando em processos de acreção e/ou erosão praial (Klein at al., 2015). A erosão também pode estar relacionada à ação antrópica que, através de construções sobre o ambiente costeiro, intensifica os processos erosivos tornando as ocupações próximas ao ambiente praial vulneráveis ao ataque das ondas em episódios tempestuosos mais intensos (Horn et al., 1998).

Outro fator que vem causando prejuízos materiais às zonas litorâneas é a maré de tempestade, que provoca inundações e erosão costeira, e ocorre pela sobre-elevação do nível do mar durante eventos de tempestade, ocasionado por fortes e persistentes ventos que empilham água na costa, sendo geralmente associados à passagem de frentes frias e ciclones extratropicais (Rudorff et al., 2005). Segundo Rudorff et al. (2005), entre 1997 e 2003, nos municípios litorâneos de Santa Catarina, foram identificados 26 registros de eventos de marés meteorológicas associadas a ondas de tempestade. Krueger (2011) identificou 60 eventos desta natureza entre 2000 e 2010 na mesma região. Neste contexto, devido ao aumento populacional nas zonas litorâneas, fica evidente a necessidade de uma maior preocupação com a vulnerabilidade das comunidades a estes eventos.

Segundo Clark (1993) e Souza et al. (2005), as áreas com problemas de erosão costeira são aquelas que apresentam pelo menos uma das seguintes características:

- altas taxas de erosão ou erosão recente significativa;

- taxas de erosão baixa ou moderada em praias com estreita faixa de areia e localizadas em áreas altamente urbanizadas;

- praias que necessitam ou que já possuem obras de proteção ou contenção de erosão;

- praias reconstruídas artificialmente e que seguem um cronograma de manutenção.

Com a finalidade de conter o avanço do mar e proteger a costa da ação erosiva, investimentos públicos e privados são comumente demandados, visando a construção de obras com diferentes níveis tecnológicos para a defesa litorânea. Airoldi et al. (2005) e Bruun (2013) 
destacaram que as obras podem ter por objetivo a proteção dos equipamentos urbanos, a recuperação do perfil praial e a consolidação de infraestruturas urbanas. Já Koerner et al. (2013) estudaram o efeito das estruturas de contenção na erosão da linha de costa, resultado da urbanização mal planejada da zona costeira. Eventualmente, obras que envolvem alta tecnologia não garantem total eficácia (Paula, 2015), sendo necessária uma avaliação elaborada da região para definição da obra mais adequada e que assegure os resultados esperados. Desta forma, é constatada a importância do estudo, planejamento e investimento em novas tecnologias, que possibilitem a garantia da proteção da dinâmica costeira e que impeçam a ocorrência de maiores problemas ambientais na região determinada, visto que, os estudos sobre erosão costeira são relativamente recentes no Brasil, tendo recebido grande expressão somente a partir da década de 1990 (Souza et al., 2005).

No Brasil, as pressões socioeconômicas nas zonas costeiras vêm desencadeando, ao longo do tempo, um processo acelerado de urbanização não planejada e intensa degradação dos recursos naturais, os quais são uma ameaça à sustentabilidade econômica e à qualidade ambiental e de vida das populações (Souza, 2004). Deste modo, há centenas de áreas litorâneas onde o processo de alteração ambiental tornou-se bastante acentuado e prejudicial, requerendo medidas de recuperação, contenção e proteção da costa (Souza, 2009).

De acordo com Pianca et al. (2010), as ondas geradas pelos ventos nos oceanos são responsáveis pela transferência de grande quantidade de energia para a zona litorânea, definindo uma grande variedade de processos costeiros. Adicionalmente, conhecer o clima de ondas de uma região é fundamental para as atividades desenvolvidas em sua zona costeira. Estudos realizados por Pianca et al. (2010) e Guimarães et al. (2017) destacam que os locais com maiores valores de altura significativa e de potencial energético estão relacionados à Região Sul de toda a plataforma brasileira. Segundo Guimarães et al. (2017), enquanto algumas áreas costeiras no Sul do Brasil atingem aproximadamente $2,0 \mathrm{~m}$ de altura de ondas, as áreas ao norte revelam valores em torno de 1,0 m. Já em relação à magnitude do potencial energético das ondas, este autor afirma que a discrepância das regiões Norte e Sul é ainda maior; enquanto no Sul os valores da costa atingem até $11 \mathrm{~kW} / \mathrm{m}$, no Norte os valores são de cerca de $5 \mathrm{a} 8 \mathrm{~kW} / \mathrm{m}$.

Silva et al. (2007) concluem que o estudo da dinâmica costeira envolve a avaliação da distribuição da energia das ondas, dos padrões de dispersão de sedimentos e do balanço de sedimentos ao longo da costa, possibilitando a previsão de mudanças na zona litorânea e permitindo a compreensão da geologia e dos processos praiais, que é essencial para um adequado gerenciamento costeiro e para a instalação de obras de engenharia ao longo da costa. Desta forma, torna-se essencial avaliar a distribuição do potencial energético das ondas ao longo da costa, já que são os principais responsáveis pelo transporte de sedimentos litorâneos e pelos processos erosivos e de acumulação (Griggs e Trenhaile, 1994).

Particularmente no estado de Santa Catarina, a erosão vem causando sérios impactos ambientais e socioeconômicos aos municípios. Dentre as várias consequências que a erosão pode trazer às praias, aos ambientes naturais e às atividades antrópicas na zona costeira, Souza et al. (2005) destacam os seguintes: redução na largura da praia e recuo da linha de costa, desaparecimento da zona de pós-praia, perda e desequilíbrio de habitats naturais, aumento na frequência $\mathrm{e}$ magnitude de inundações costeiras, aumento da intrusão salina no aquífero costeiro e nas drenagens superficiais da planície costeira, perda de propriedades e bens públicos e privados ao longo da linha de costa, destruição de estruturas artificiais paralelas e transversais à linha de costa, perda do valor imobiliário de habitações costeiras e do valor paisagístico da praia e, comprometimento do potencial turístico da região, prejuízos nas atividades socioeconômicas e gastos astronômicos com a recuperação de praias e reconstrução da orla marítima (incluindo propriedades públicas e privadas, equipamentos urbanos diversos e estruturas de apoio náutico, de lazer e de saneamento).

Bonetti et al. (2017) analisaram a suscetibilidade à erosão das praias arenosas do estado de Santa Catarina utilizando uma abordagem analítica de classificação de risco, baseados na investigação de 302 pontos, durante 40 dias e utilizando 32 geoindicadores. Os resultados demonstraram que a maioria dos pontos amostrados foi classificada em torno de graus intermediários de suscetibilidade, com uma ligeira tendência para níveis mais elevados. Assim, tornase a evidente a necessidade de uma maior preocupação com o litoral catarinense, visto que regularmente sofre influência de ciclones extratropicais e outros sistemas de tempestades que frequentemente atingem o sul do Brasil.

Os municípios costeiros do estado de Santa Catarina têm sofrido devido aos processos erosivos 
nos últimos anos. Klein et al. (2015) afirmam que foram realizados investimentos por órgãos municipais em projetos para a proteção das áreas degradadas do litoral catarinense, através da disposição de rochas sobre a linha de praia e a construção de muros (sea-walls), visando proteger a orla frente aos sucessivos eventos episódicos, e a consequente retração da linha de praia. Entretanto, segundo CTTMar (1999), estas soluções não foram eficazes e, como resultado, observou-se uma amplificação dos processos erosivos nas áreas imediatamente adjacentes, resultando na destruição das próprias estruturas edificadas.

Oleinik et al. (2017) avaliaram o potencial energético das ondas na costa Sul-sudeste brasileira e concluíram que na costa catarinense, o local que possui ondas com maior potencial energético pertence ao Cabo de Santa Marta, em Laguna/SC. Localizada a $120 \mathrm{~km}$ ao sul da capital Florianópolis, Laguna abriga 51.562 habitantes (IBGE, 2016), sendo o município que mais cresce nesta região do estado. O litoral centro-sul de Santa Catarina apresenta um crescimento demográfico considerável devido à urbanização acelerada e desordenada, resultando em impactos ambientais significativos na região, como poluição dos corpos hídricos, processos erosivos da região de dunas e perda de vegetação litorânea (Scherer et al., 2006).

Inserido neste contexto, o presente trabalho tem como finalidade realizar a análise da região costeira do estado de Santa Catarina, para identificar o alcance do potencial energético das ondas sobre a costa e, assim, definir a área que está sofrendo os maiores impactos ondulatórios e, consequentemente, tornando-se mais vulnerável à erosão. Por conseguinte, será proposta a instalação de uma estrutura que atue como proteção costeira, tendo a capacidade de atenuar os efeitos causados pela ação energética das ondas e, portanto, consiga evitar que ocorra uma maior degradação do ambiente.

\section{Material e métodos}

\section{Área de estudo: Litoral Catarinense, Brasil}

$\mathrm{O}$ estudo concentra-se no litoral do estado de Santa Catarina, localizado na Região Sul do Brasil, entre os paralelos $25^{\circ} 5^{\prime}$ 'S e $28^{\circ} 37^{\prime}$ 'S e os meridianos $48^{\circ} 25^{\prime}$ " e $48^{\circ} 49^{\prime}$ ' $\mathrm{W}$, estendendo-se por $561,40 \mathrm{~km}$ (Moraes, 1995). Santa Catarina possui 36 municípios costeiros, totalizando aproximadamente $9.094,40 \mathrm{~km}^{2}$ de área terrestre e $5.894 \mathrm{~km}^{2}$ de área oceânica (Scherer et al., 2006). As praias de areia são a característica geomórfica mais presente na costa de Santa Catarina, representando quase $58 \%$ de sua extensão (Klein et al., 2016).

O litoral catarinense é orientado no sentido Norte-sul desde a divisa com o Estado do Paraná até a altura do Cabo de Santa Marta, e o extremo sul do estado apresenta orientação SudoesteNordeste até a divisa com o estado do Rio Grande do Sul (Scherer et al., 2006), representando cerca de $7 \%$ de todo o litoral brasileiro. A planície costeira encontra-se em contato direto com as águas da porção sul do Oceano Atlântico.

Horn Filho et al. (2004) destacam que os ventos predominantes no litoral catarinense são originados de nordeste, sudoeste e sudeste, e são responsáveis pela configuração das dunas litorâneas pretéritas e atuais. Já para as ondulações, estes autores afirmam que são geradas principalmente pelos ventos do sudeste do cinturão subpolar do Atlântico Sul e as correntes litorâneas propiciam uma deriva resultante direcionada para nordeste, que é um dos fatores mais importantes responsáveis pela formação das praias do litoral.

As ondas de águas profundas na região de estudo variam de 0,5 a $2,0 \quad \mathrm{~m} \quad \mathrm{e}$ vêm predominantemente de leste a sudeste, enquanto as ondas de tempestade podem atingir alturas médias de 3,5 m, concentradas a partir do sul (Klein et al., 2016). Segundo Rudorff e Bonetti (2010), as maiores ondulações ocorrem no outono e no inverno; entretanto, ondas grandes, com altura significativa de 4,0 m estão presentes em todas as estações do ano, sendo que, no outono, o valor modal de altura significativa é de $1,5 \mathrm{~m} \mathrm{e}$, no inverno, varia de 1,25 a $2,5 \mathrm{~m}$.

O litoral de Santa Catarina é regularmente influenciado por ciclones extratropicais e outros sistemas de tempestades (Muler e Bonetti, 2014), que podem se desenvolver nas proximidades do litoral e causar erosão na praia e inundações costeiras. As amplitudes das marés são inferiores a $1,2 \mathrm{~m}$, típico de um regime de micro marés. No litoral sul e sudeste brasileiro, as marés são predominantemente semi-diurnas, com amplitudes variando de 0,46 a $1,06 \mathrm{~m}$ (Klein, 2004).

Os processos de erosão já foram descritos em Santa Catarina e foram associados a mudanças progressivas da posição do litoral ou a eventos específicos de transferência de energia a partir de ondas altas (Bonetti et al., 2017). Entretanto, apesar de muitos estudos terem sido realizados no litoral do estado de Santa Catarina, visando definir e mapear as áreas mais propensas ao risco da erosão costeira, e sendo adotadas diversas metodologias, ainda há uma escassez bibliográfica em relação a pesquisas sobre alternativas que visem reverter esta 
situação, e consigam, portanto, identificar uma solução eficaz para a problemática em questão.

\section{Modelo Numérico}

O trabalho foi desenvolvido utilizando o modelo numérico TOMAWAC para realizar as simulações. Este modelo faz parte do sistema de modelagem TELEMAC (www.opentelemac.org). O TOMAWAC é um modelo de ondas de terceira geração que calcula o estado do mar resolvendo a equação de conservação da densidade de ação das ondas (Eq. 1), para o espectro direcional da onda: $\frac{\partial N(f, \theta)}{\partial t}+\frac{\partial \dot{x} N}{\partial x}+\frac{\partial \dot{y} N}{\partial y}+\frac{\partial \dot{k}_{x}}{\partial k_{x}}+\frac{\partial \dot{k}_{y}}{\partial k_{y}}=Q\left(k_{x}, k_{y}, x, y, t\right) \ldots . .(1)$

onde $N$ é o espectro direcional da onda, $k x$ e $k y$ são os componentes nas direções $x$ e $y$ do vetor do número de onda e $t$ é o tempo. A Equação (1) representa que, em uma situação geral de ondas que se propagam em um ambiente não homogêneo e instável, a densidade da ação da onda é preservada dentro dos termos de origem e de dissipação, definidos por $Q$.

O TOMAWAC calcula ondas geradas pelo vento, levando em consideração os principais processos físicos envolvidos como empolamento, refração induzida pela profundidade e por correntes, dissipação de energia por rebentação parcial (whitecapping), dissipação por fricção com o fundo e interações não lineares entre ondas. Em cada ponto da malha computacional, este modelo tem a capacidade de calcular a altura significativa, a frequência média e a direção média das ondas, como também as correntes induzidas pelas ondas e a frequência de pico das ondas. No entanto, o TOMAWAC não leva em consideração a difração e a reflexão das ondas.

Para resolver a Equação (1), o TOMAWAC divide o espectro direcional da ação da onda $(\mathrm{N})$ em um número finito de frequências de ondas $\left(f_{i}\right)$ e direções $\left(\theta_{i}\right)$ e resolve a Equação (1) para cada componente $\left(\mathrm{f}_{\mathrm{i}}, \theta_{\mathrm{i}}\right)$. O espectro direcional da energia das ondas, denotado por $\mathrm{E}(\mathrm{f}, \theta)$, pode ser associado com N (f, $\theta)$ à Equação (2).

$E(f, \theta)=N(f, \theta) \rho g$

onde $\rho$ é a massa específica de água, g é a aceleração da gravidade e $\sigma$ é a frequência angular das ondas dada por $\sigma=2 \pi f$. A integração de $E(f, \theta)$ ao longo das frequências e direções discretizadas produz a energia por unidade de área das ondas multidirecionais aleatórias (Eq. (3)).

$\sum_{f}^{f+d f} \sum_{\theta}^{\theta+d \theta} \frac{1}{2} \rho g a_{m}^{2}=E(f, \theta) d f d \theta$.
Os dados de condições de contorno superficiais, correspondentes ao ano de 2014, foram construídos com dados de reanálise atmosféricos da NOAA (National Oceanic and Atmospheric Administration), com resolução temporal de 6 horas e resolução espacial de 0,5 graus. O contorno oceânico foi forçado por dados de altura significativa, período de pico e direção de pico, obtidos através dos dados do modelo de previsão de ondas WAVEWATCH III, com resolução temporal de 3 horas e resolução espacial de 0,5 graus, também para o ano de 2014 .

Para a geração da malha computacional foi utilizado o software Blue Kenue (desenvolvido pelo CHC - Canadian Hidraulic Centre), com os limites das bordas costeiras e oceânicas devidamente georreferenciadas, cobrindo toda a extensão da costa catarinense e a região norte do litoral do Rio Grande do Sul. A malha gerada foi do tipo não estruturada, com elementos triangulares que permitem a representação dos domínios de estudo a partir de níveis de refino não uniformes, possibilitando a obtenção de maiores resoluções em regiões específicas (Lynch et al., 1996). O domínio espacial é representado por uma malha com 195.436 nós, onde a distância entre os vértices dos elementos triangulares é de $15.000 \mathrm{~m}$ na zona oceânica, $500 \mathrm{~m}$ na região costeira e $80 \mathrm{~m}$ na área de estudo.

$\mathrm{Na}$ execução da rampa, a largura da estrutura foi definida através da escolha de dois pontos da malha próximos à costa, onde a profundidade foi fixada como mínima, e de modo que envolvesse totalmente a largura do pontal, que é exatamente a região onde ocorrem os maiores valores de potencial energético das ondas. Para a delimitação do comprimento, optou-se por uma distância considerável, tendendo a manter a batimetria constante ao longo da rampa, propiciando a dissipação contínua da energia das ondas, e evitando uma estrutura com grande declividade, que poderia causar um efeito contrário ao objetivo do estudo.

\section{Resultados e discussão}

Através de simulações de ondas forçadas pelo vento ao longo do ano de 2014 , foi verificado que a região da costa catarinense com valores energéticos mais intensos pertence ao Cabo de Santa Marta, localizado em Laguna (Fig. 1). 


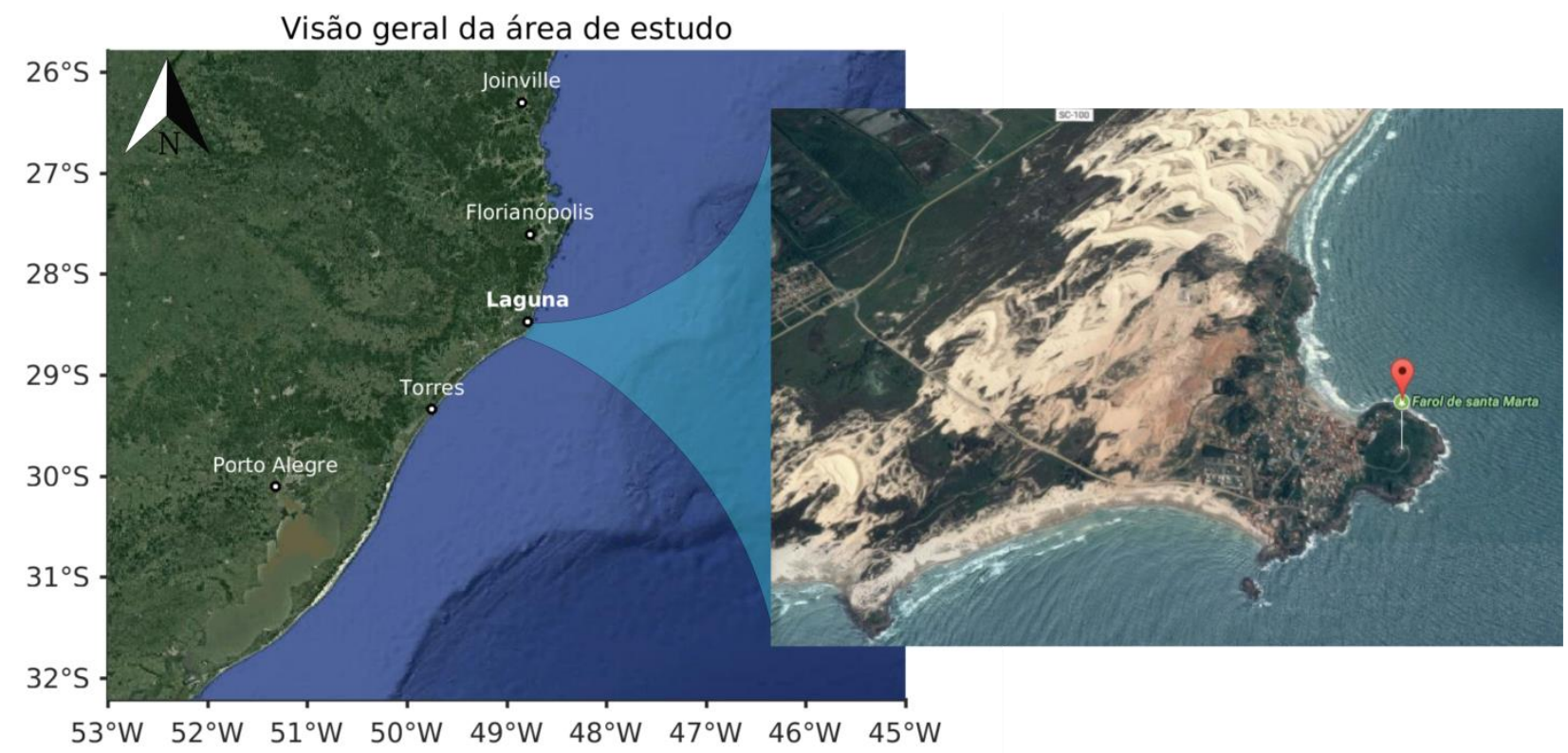

Figura 1. Indicação do Farol de Santa Marta, em Laguna/SC, onde será proposta a instalação da rampa (Imagem sobreposta do Google Maps, Airbus, DigitalGlobe, 2017).

No Cabo de Santa Marta, Oleinik et al. (2017) observaram que a altura significativa média das ondas era de aproximadamente $1,4 \mathrm{~m}$, ocorrendo um aumento notável nos meses de maio e setembro (que são aproximadamente os meses que marcam a transição entre o clima frio e quente), e que o período de pico apresentava maiores valores no outono e no inverno e menores na primavera e no verão, ocorrendo um aumento significativo no mês de maio.

Para este estudo foi constatado que a altura significativa média das ondas no Cabo de Santa Marta possui os valores mais elevados em relação a todo o litoral catarinense (Fig. 2), atingindo alturas que variam de 1,2 a 1,4 m nas proximidades da costa.

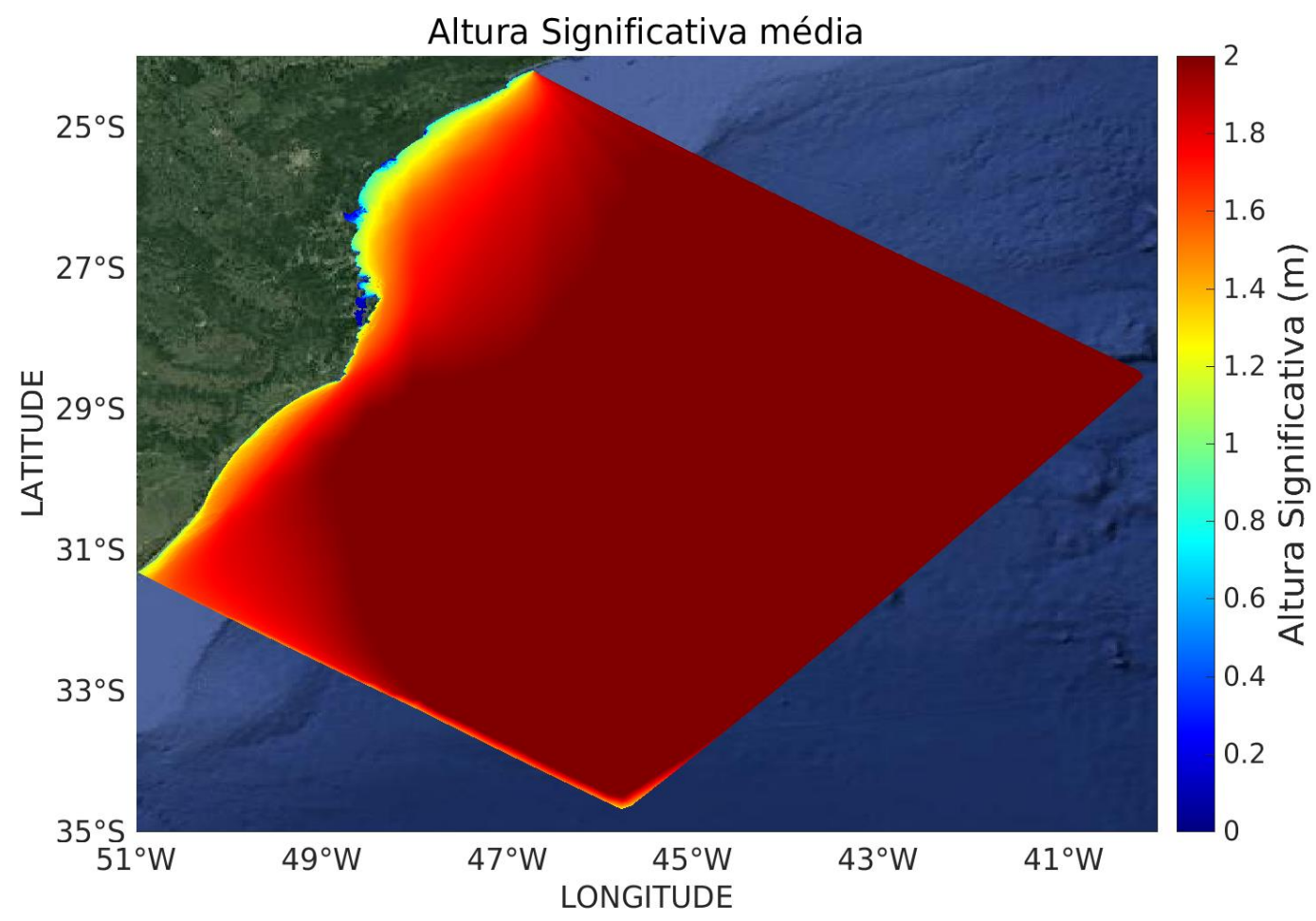

Figura 2. Região de estudo na costa catarinense para o ano de 2014. A barra de cores representa a superfície média de Altura Significativa variando de zero a $2 \mathrm{~m}$ (Imagem sobreposta do Google Maps, TerraMetrics, 2017). 
Devido à extensão da área afetada pela ação das ondas no Cabo de Santa Marta, foi determinada a utilização de uma estrutura com seção transversal em rampa, de forma que atenuasse continuamente o potencial energético das ondas até que estas atingissem a costa. A rampa utilizada nas simulações computacionais foi

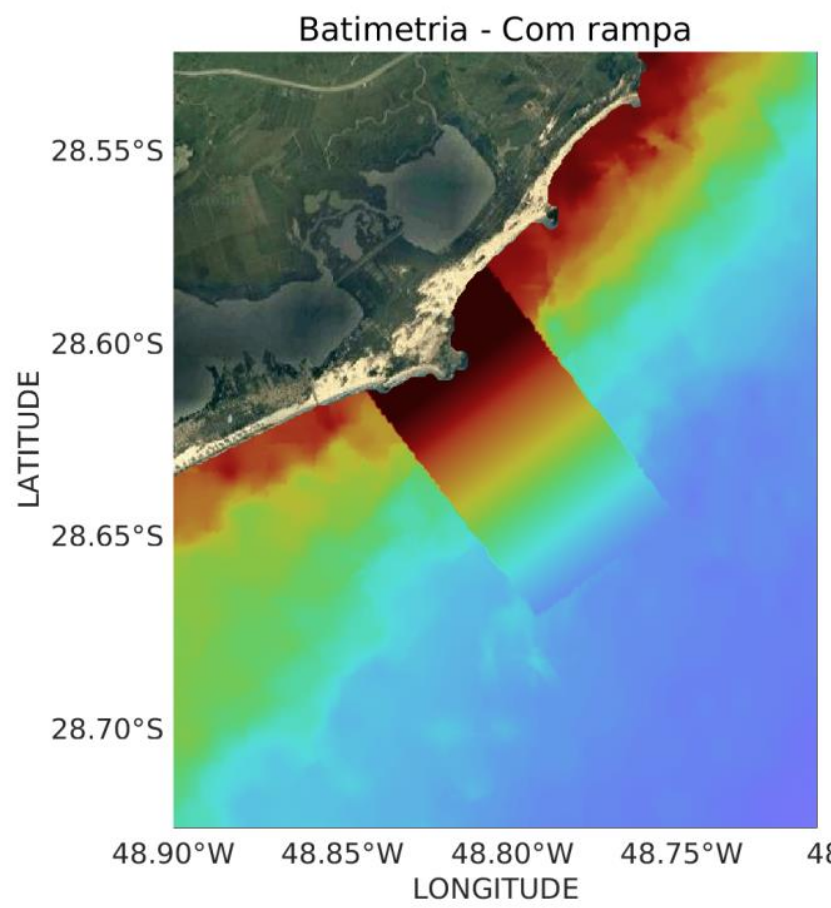

definida inicialmente com $7.000 \mathrm{~m}$ de comprimento em direção ao oceano e com $3.000 \mathrm{~m}$ de largura ao longo da costa, de modo que envolvesse totalmente a área que sofre a ação das ondas mais energéticas, optando-se por nivelar a batimetria no entorno do pontal (Fig. 3).

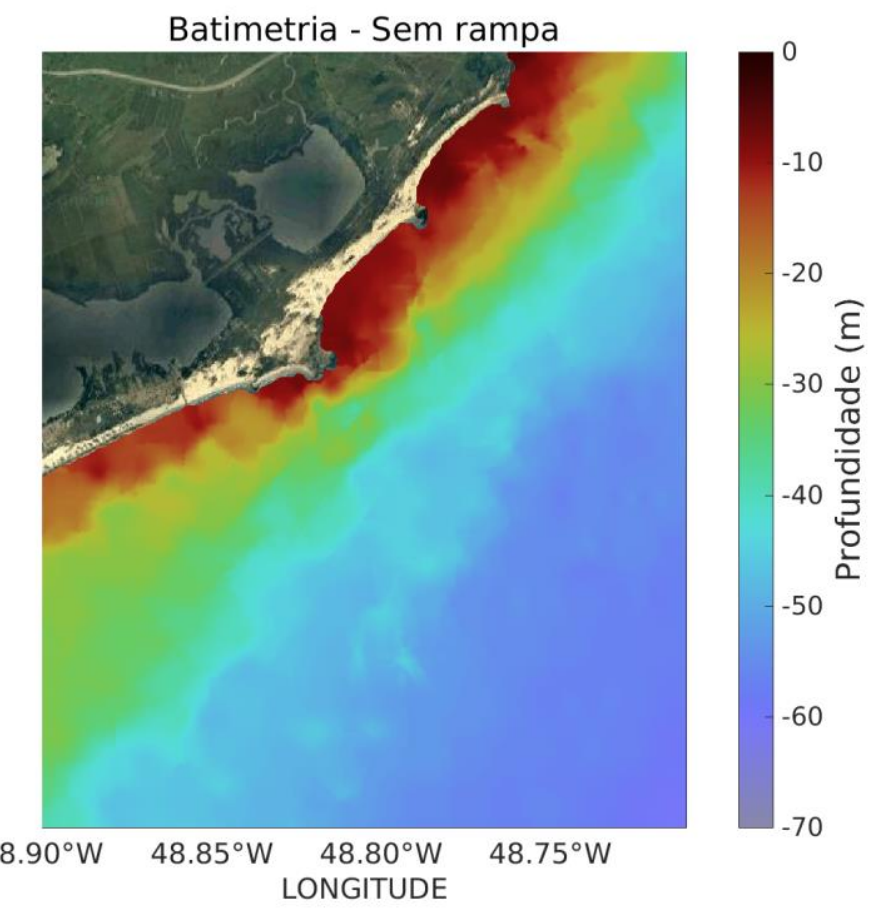

Figura 3. Área de estudo nos cenários com e sem rampa para o ano de 2014. A barra de cores representa a batimetria variando de zero a $70 \mathrm{~m}$ de profundidade (Imagem sobreposta do Google Maps, Airbus,

DigitalGlobe, Landsat/Copernicus, 2017).

Após a realização das devidas simulações, pode ser verificada a eficiência da instalação da rampa no Cabo de Santa Marta, através da análise da altura significativa e do potencial energético na região.

No cenário natural, onde a rampa não havia sido instalada, a altura significativa das ondas possuía valores bastante acentuados, atingindo de 1,2 a 1,4 m nas proximidades do pontal. Entretanto, após a instalação da estrutura, os valores diminuíram expressivamente, resultando em aproximadamente $0,1 \mathrm{~m}$ de altura significativa (Fig. 4). 

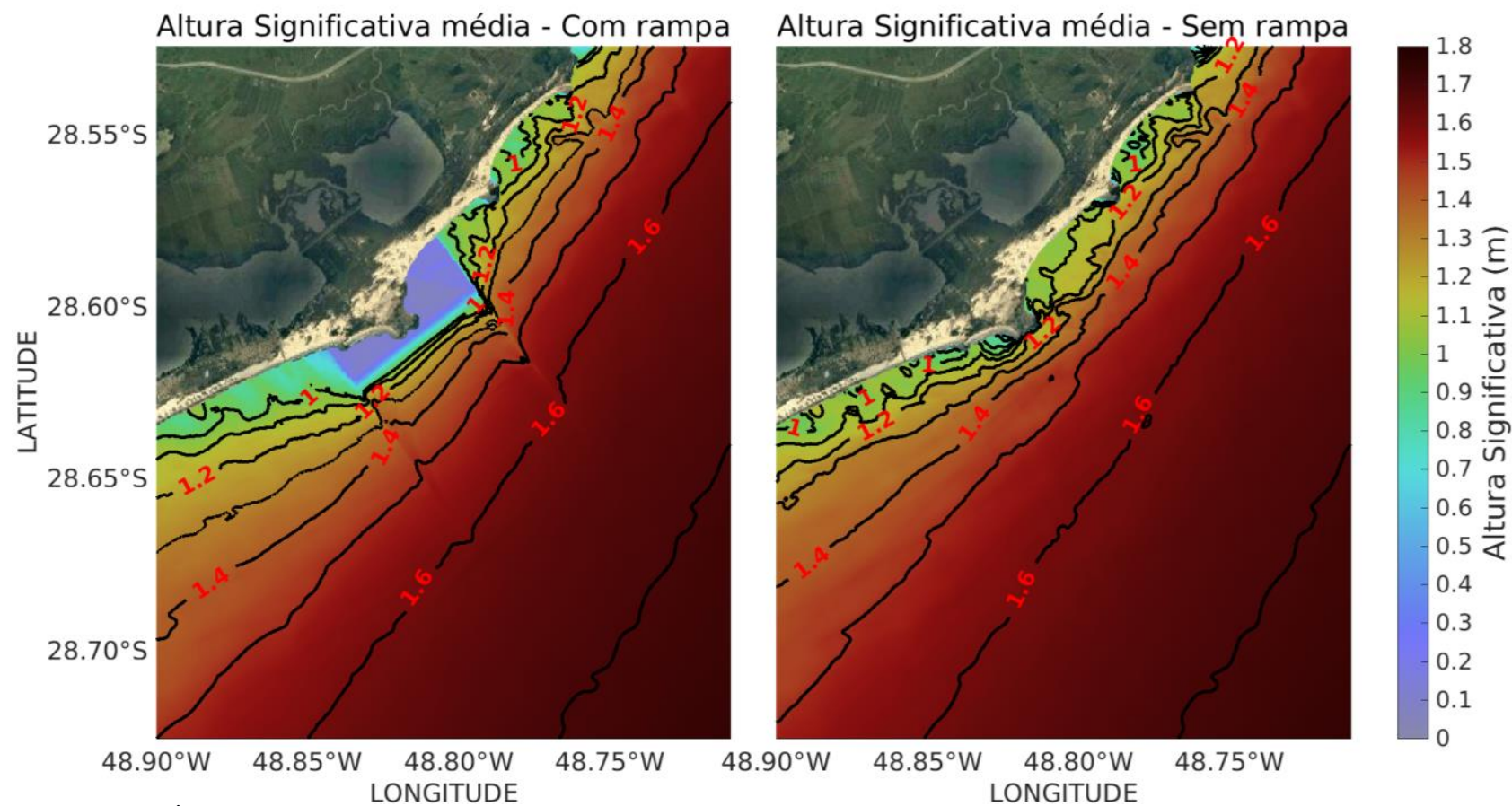

Figura 4. Área de estudo nos cenários com e sem rampa, para o ano de 2014. A barra de cores representa a superfície média de Altura Significativa variando de zero a 1,8 m (Imagem sobreposta do Google Maps, Airbus, DigitalGlobe, Landsat/Copernicus, 2017).

Ao analisar o potencial energético foi observado uma diminuição considerável nos resultados, conforme ocorreu com a altura significativa das ondas. Anteriormente à instalação da rampa, o

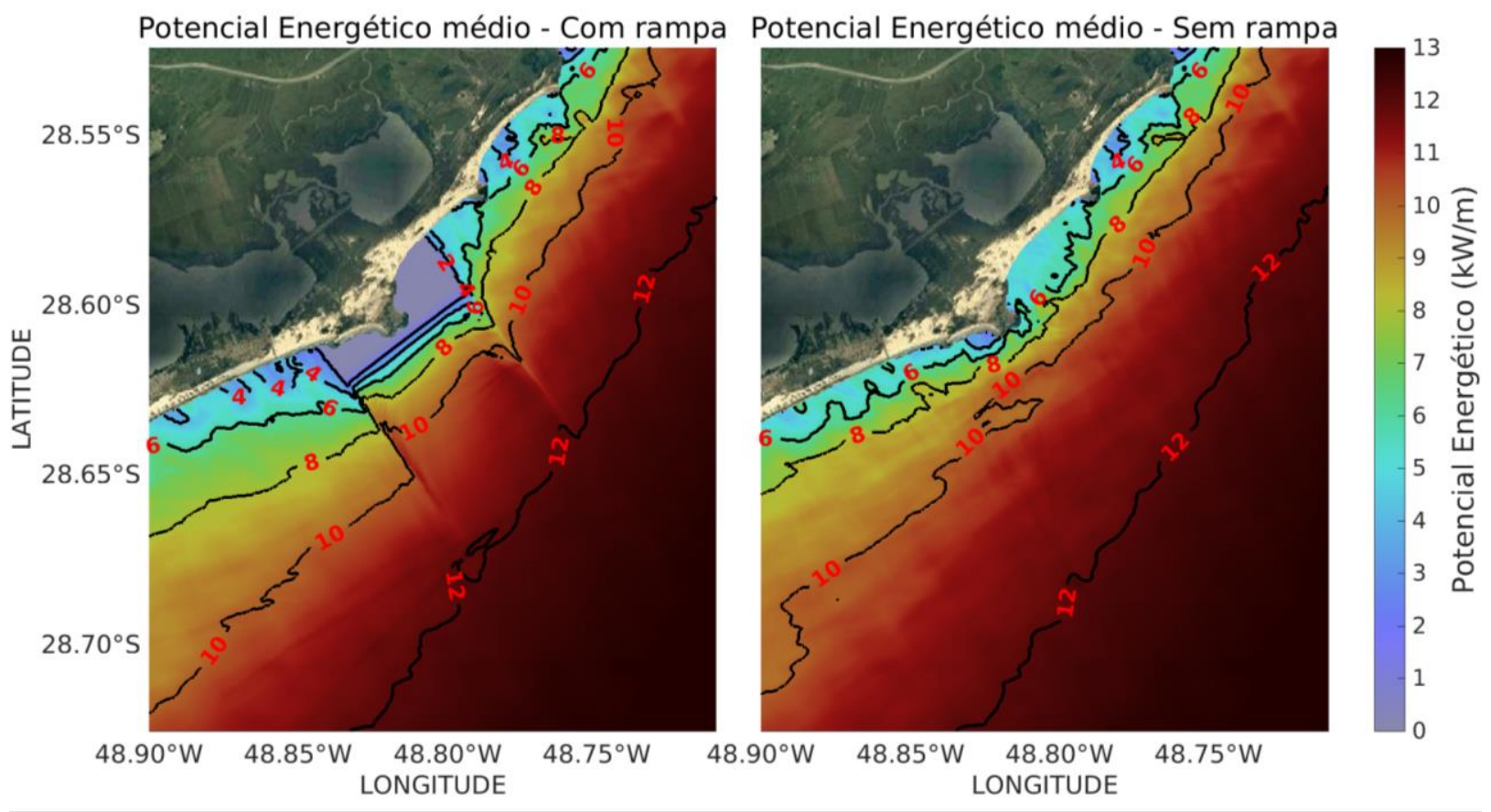

valor do potencial energético das ondas era próximo a $8 \mathrm{~kW} / \mathrm{m}$ nas proximidades da costa, e, após a instalação da estrutura, resultaram em valores abaixo de $2 \mathrm{~kW} / \mathrm{m}$ (Fig. 5).

Figura 5. Área de estudo nos cenários com e sem rampa, para o ano de 2014. A barra de cores representa a superfície média de Potencial Energético variando de zero a $13 \mathrm{~kW} / \mathrm{m}$ (Imagem sobreposta do Google Maps, Airbus, DigitalGlobe, Landsat/Copernicus, 2017).

Após a análise destes resultados, visto que a rampa conseguiu atenuar uma quantidade expressiva do potencial energético das ondas, foram realizadas outras simulações utilizando um 
comprimento de $4000 \mathrm{~m}$ para a rampa, visando uma estrutura com tamanho menor e, portanto, mais econômica. A largura de $3000 \mathrm{~m}$ foi mantida para esta situação (Fig. 6).

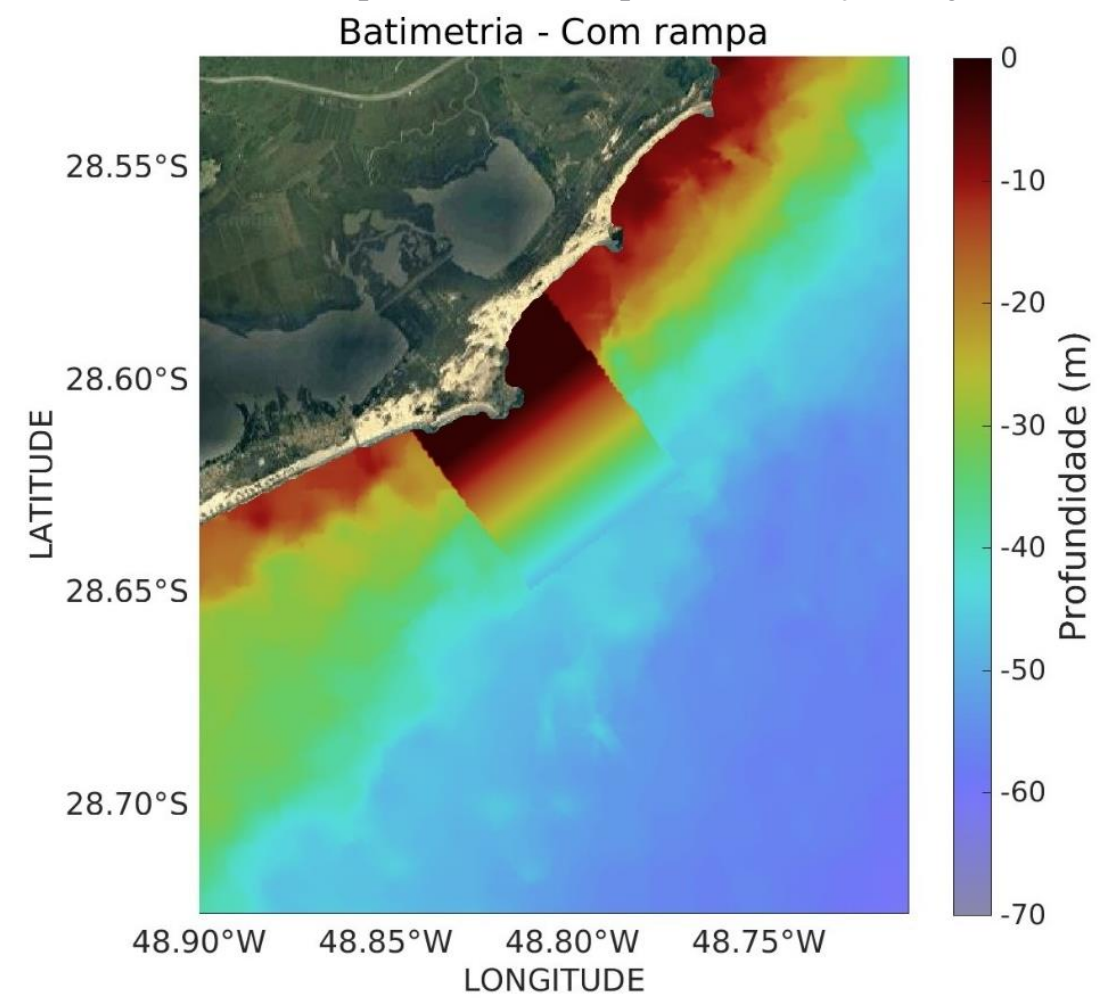

Figura 6. Área de estudo após a instalação da rampa de $3000 \mathrm{~m}$ de largura e $4000 \mathrm{~m}$ de comprimento. A barra de cores representa a batimetria variando de 0 a $70 \mathrm{~m}$ de profundidade (Imagem sobreposta do Google Maps, Airbus, DigitalGlobe, Landsat/Copernicus, 2017).

Conforme demonstrado anteriormente, no cenário natural, a altura significativa das ondas possuía valores que variavam de 1,2 a $1,4 \mathrm{~m}$ nas proximidades do pontal. Após a instalação da rampa de $4000 \mathrm{~m}$ de comprimento, houve uma diminuição expressiva, resultando em aproximadamente $0,1 \mathrm{~m}$ de altura significativa (Fig. 7). 


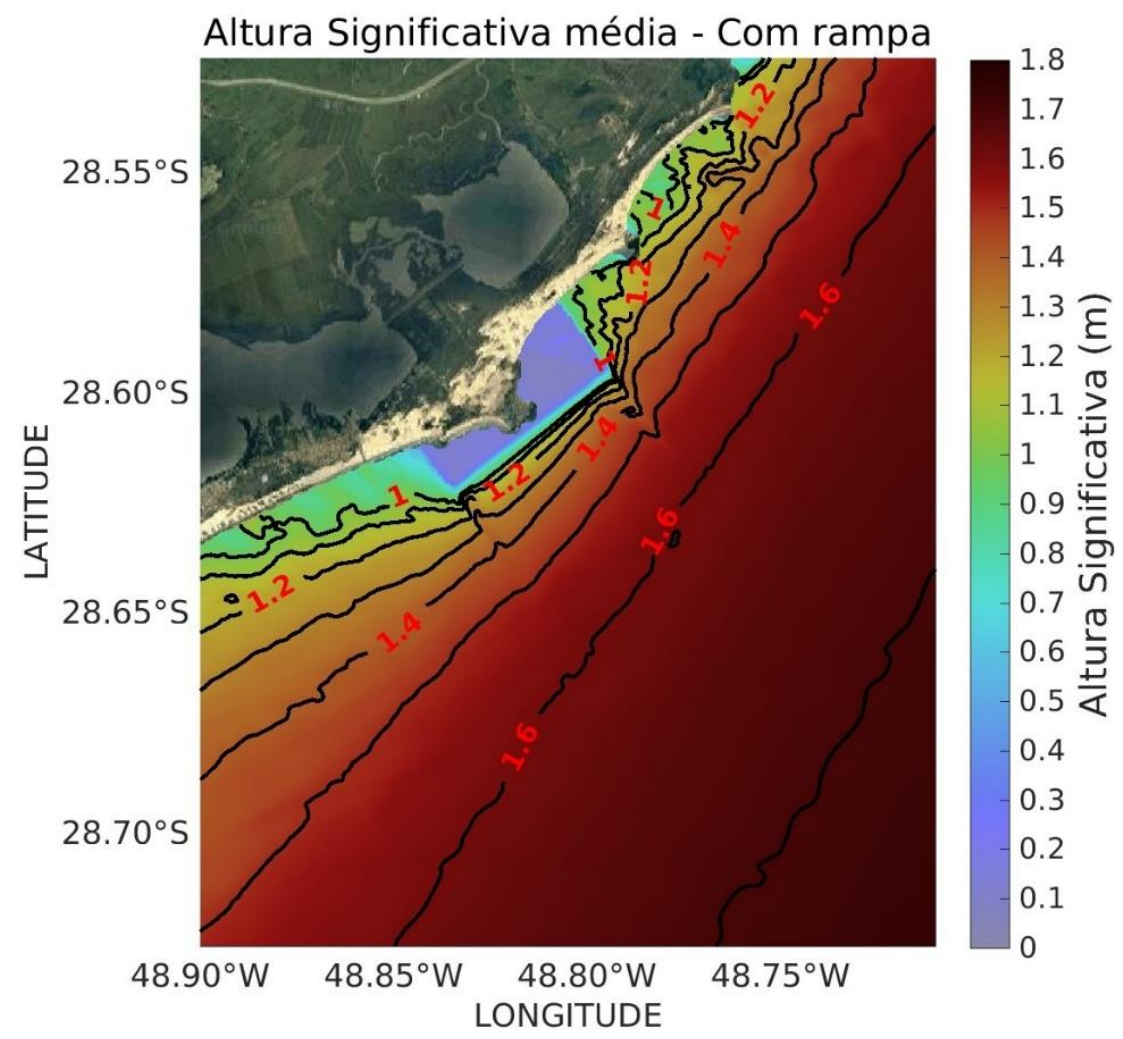

Figura 7. Área de estudo após a instalação da rampa de $3000 \mathrm{~m}$ de largura e $4000 \mathrm{~m}$ de comprimento. A barra de cores representa a superfície média de Altura Significativa variando de zero a 1,8 m (Imagem sobreposta do Google Maps, Airbus, DigitalGlobe, Landsat/Copernicus, 2017).

No caso do potencial energético, anteriormente à instalação da rampa, o valor do potencial energético das ondas era próximo a 8 $\mathrm{kW} / \mathrm{m}$ nas proximidades da costa e, após a instalação da estrutura, resultaram em valores abaixo de $2 \mathrm{~kW} / \mathrm{m}$ (Fig. 8). 


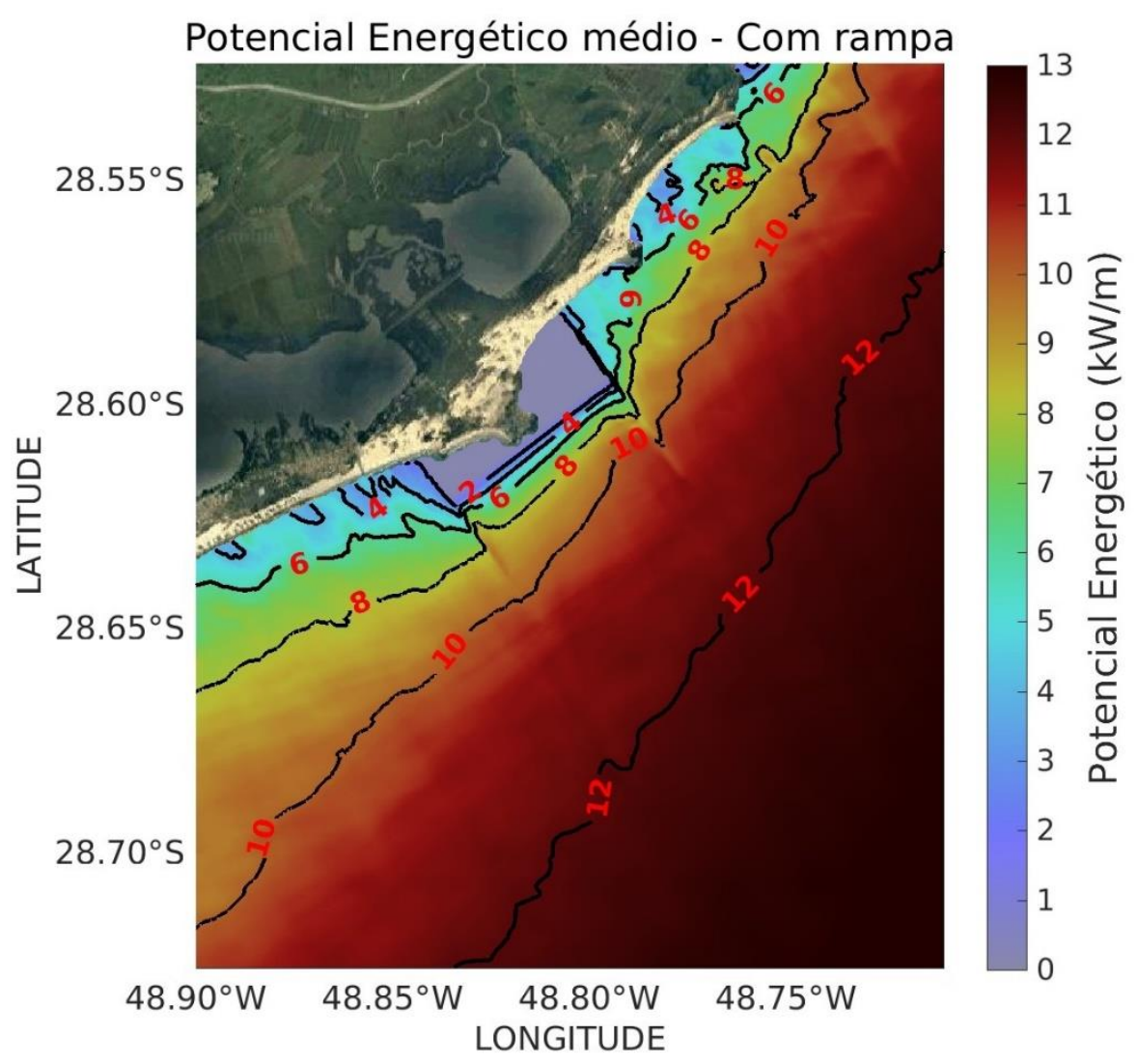

Figura 8. Área de estudo após a instalação da rampa de $3000 \mathrm{~m}$ de largura e $4000 \mathrm{~m}$ de comprimento. A barra de cores representa a superfície média de Potencial Energético variando de zero a $13 \mathrm{~kW} / \mathrm{m}$ (Imagem sobreposta do Google Maps, Airbus, DigitalGlobe, Landsat/Copernicus, 2017).

Dessa foram, foi possível comprovar que os resultados das simulações para a rampa de 4000 $\mathrm{m}$ de comprimento apresentaram valores extremamente semelhantes à rampa de $7000 \mathrm{~m}$ de comprimento. Sendo assim, optou-se por continuar o estudo considerando as medidas da menor rampa, visto que ficou evidente que o valor definido inicialmente para o comprimento da estrutura estava superestimado.

A dissipação da energia das ondas ocorreu devido à interação entre as ondas e a rampa. A instalação da estrutura proporcionou uma batimetria com declividade constante no ambiente, impedindo que este fosse muito íngreme. Assim, à medida que as ondas se deslocam em direção ao litoral, começam a interagir com o fundo, causando a dissipação contínua do seu potencial energético. Consequentemente, a altura significativa das ondas também sofre diminuição.

Dessa forma, com os dados obtidos através das simulações computacionais, foi possível calcular uma atenuação de até $98 \%$ da altura significativa das ondas que se aproximavam da costa após a instalação da rampa, e cerca de $90 \%$ do potencial energético.

Para uma melhor comprovação dos resultados, foi realizada uma análise das séries temporais de altura significativa e de potência por unidade de comprimento das ondas ao longo da rampa no decorrer do ano de 2014 (Fig. 9 e 10). 


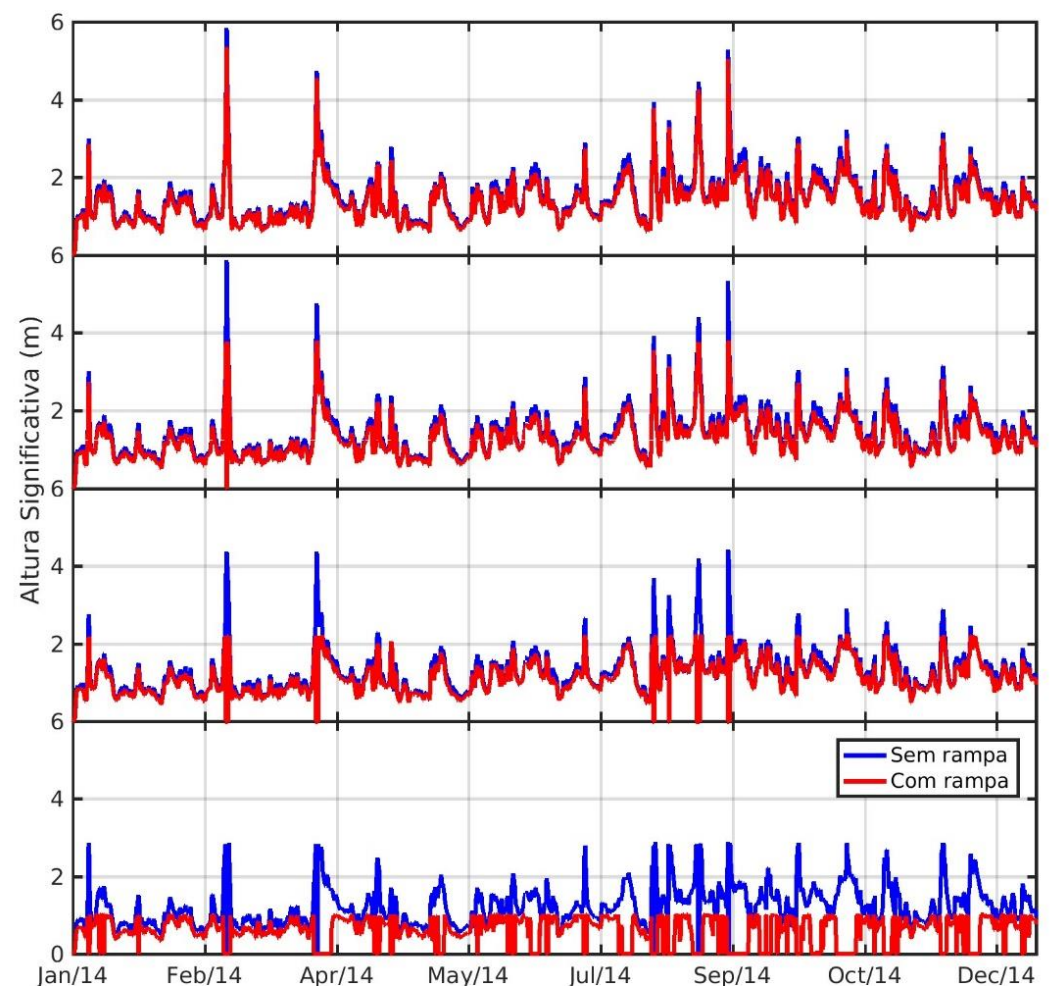

Figura 9. Séries temporais de Altura Significativa ao longo da rampa no decorrer do ano de 2014. A linha em azul representa o comportamento das ondas no cenário sem rampa e, em vermelho, após a instalação da rampa.

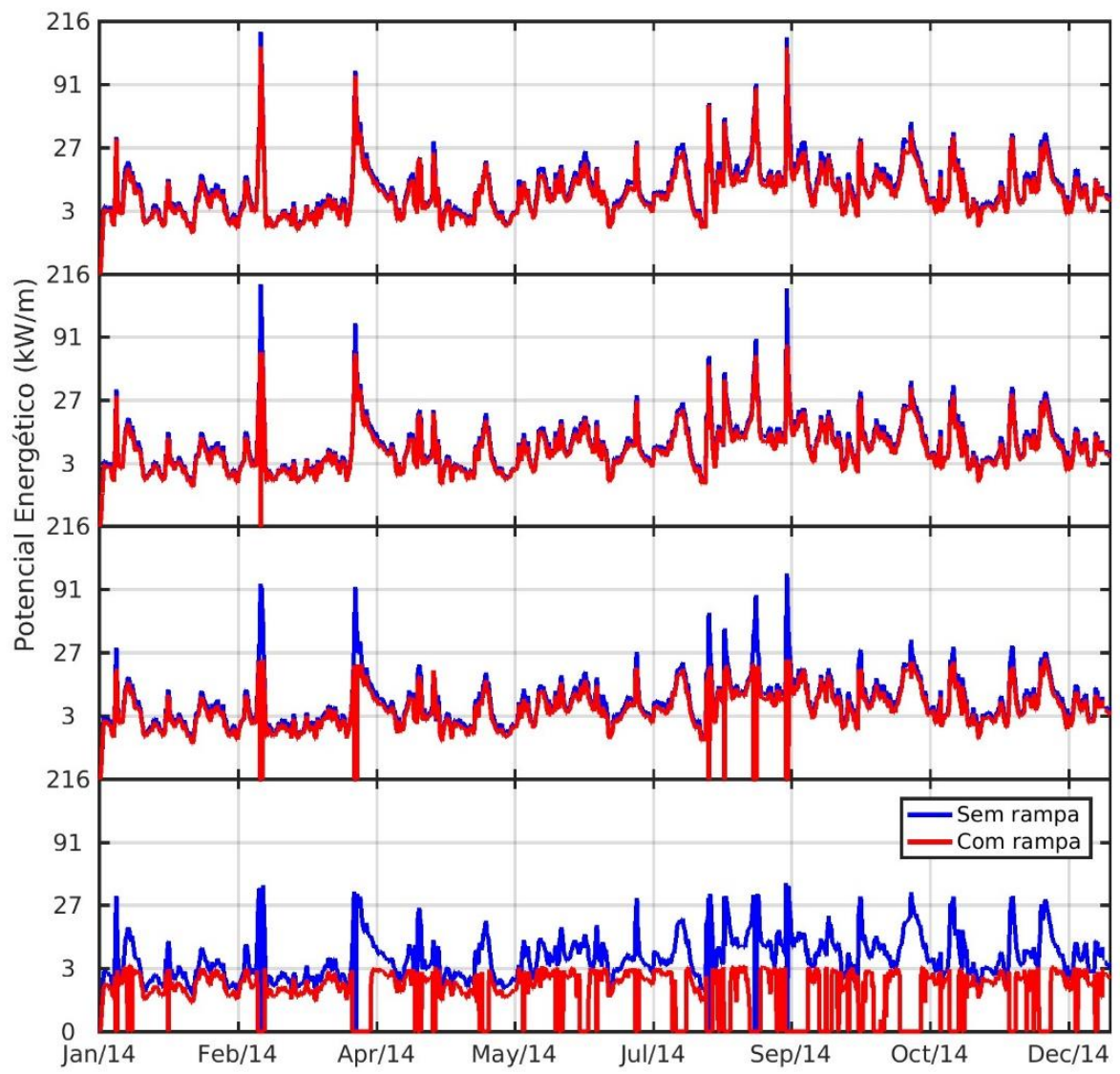

Figura 10. Séries temporais de Potencial Energético ao longo da rampa no decorrer do ano de 2014. A linha em azul representa o comportamento das ondas no cenário sem rampa e, em vermelho, após a instalação da rampa.

Trombetta, T. B., Oleini, P. H.,, Lopes, B. V., Guimarães, R. C., Marques, W. C., Isoldi L. A. 
Desta maneira, foi possível conferir através da verificação das séries temporais de altura significativa e de potencial energético, que conforme as ondas se aproximam da costa e sua energia é dissipada, os eventos extremos que ocorriam, principalmente, nos meses de fevereiro/abril e setembro, foram praticamente anulados após a inserção da rampa.

Outro fator que também pode ser verificado está relacionado à arrebentação da onda (diminuição brusca da altura significativa e do potencial energético), que passa a ocorrer a uma distância segura da costa, impedindo que as ondas tenham energia suficiente para carregar os sedimentos do litoral.

Para facilitar a visualização da estrutura, uma ilustração tridimensional da malha foi inserida a seguir, demonstrando a posição da rampa em relação à batimetria.

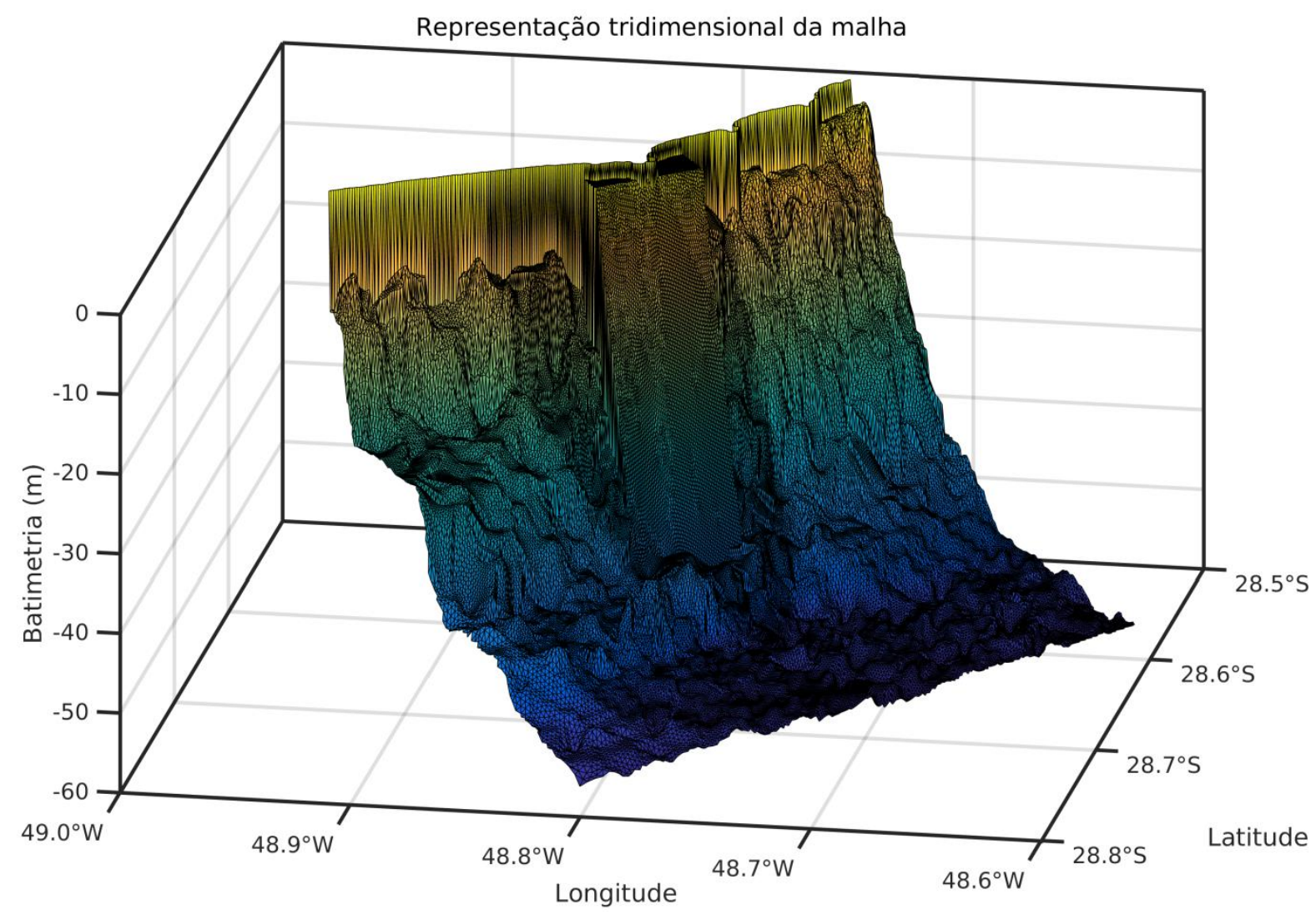

Figura 11. Representação tridimensional da batimetria da zona costeira.

Além disso, para permitir um melhor entendimento do estudo, as Figuras 12 e 13 demonstram a diferença média para a altura significativa e o potencial energético dos cenários com e sem rampa, resultando em valores negativos na região de estudo e, assim, conferindo a validade dos dados apresentados anteriormente. 


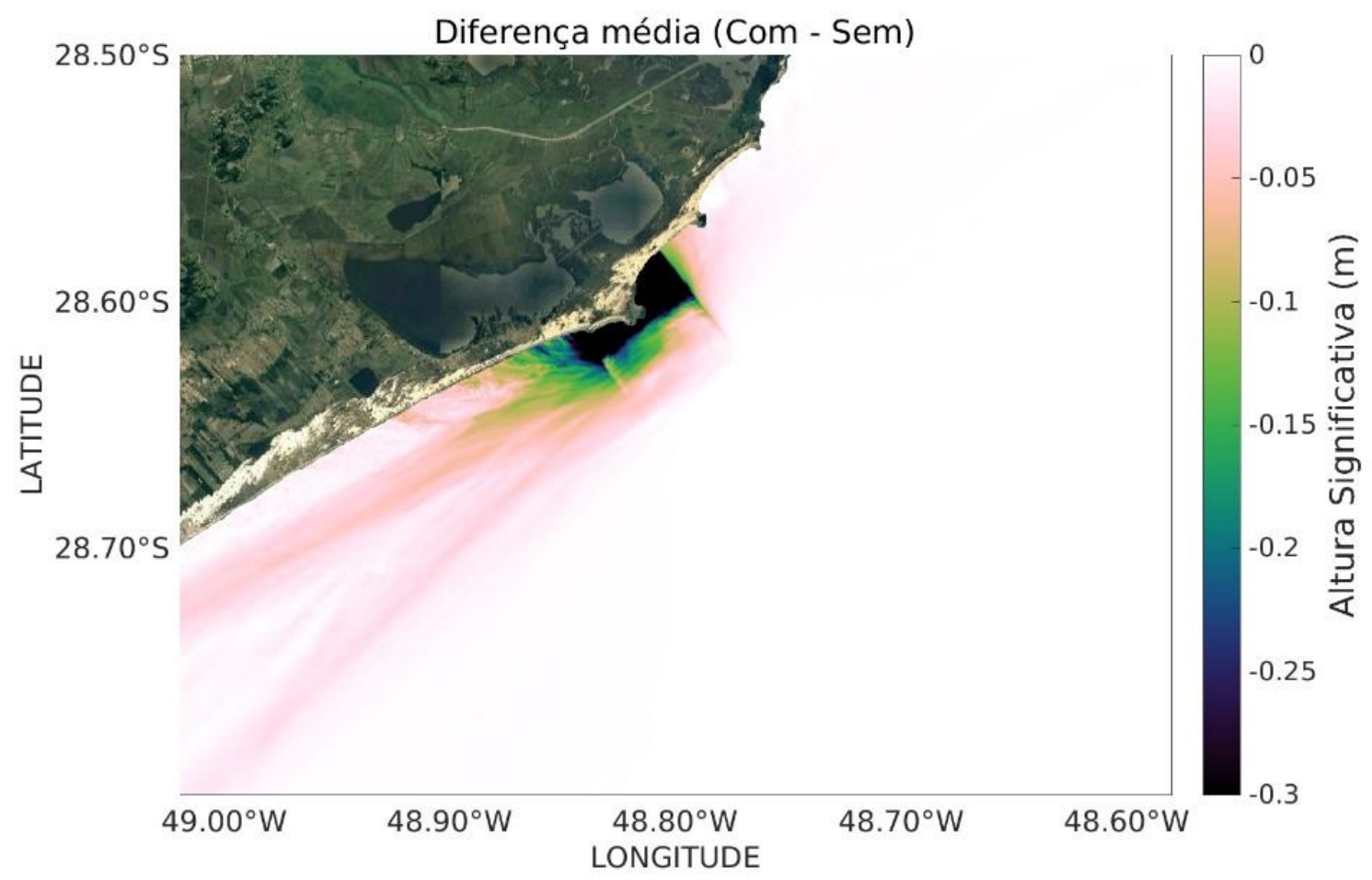

Figura 12. Diferença média da Altura Significativa das ondas nos cenários com e sem rampa na área de estudo. A barra de cores representa a superfície média de Altura Significativa variando de zero a $-0,3 \mathrm{~m}$ (Imagem sobreposta do Google Maps, Airbus, DigitalGlobe, Landsat/Copernicus, 2017).

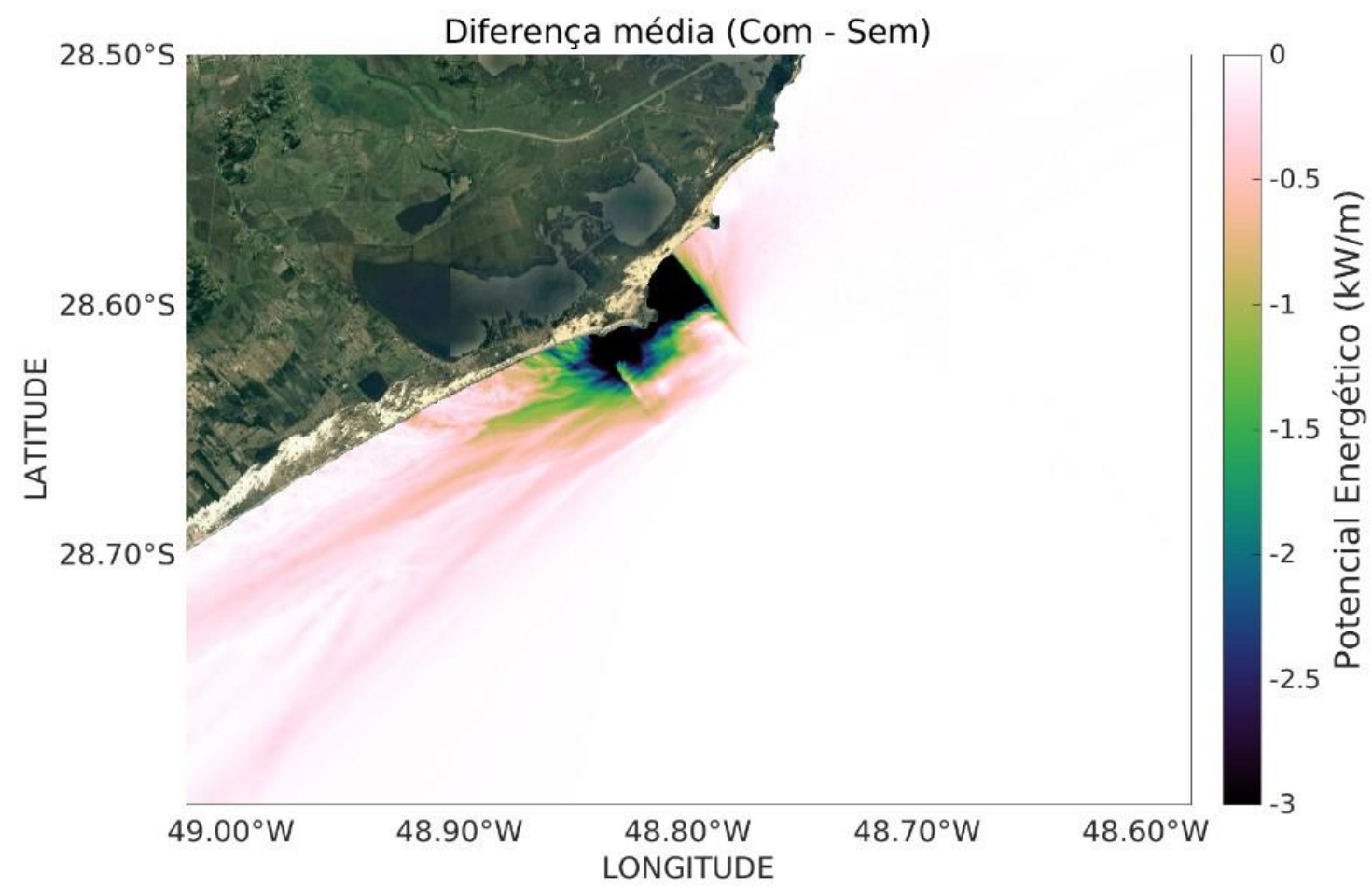

Figura 13. Diferença média do Potencial Energético das ondas nos cenários com e sem rampa na área de estudo. A barra de cores representa a superfície média de Potencial Energético variando de zero a $-3 \mathrm{~kW} / \mathrm{m}$ (Imagem sobreposta do Google Maps, Airbus, DigitalGlobe, Landsat/Copernicus, 2017).

Pode-se observar também que, devido à direção predominante do fluxo de energia das ondas, as regiões ao sul da instalação tiveram uma leve redução da altura significativa das ondas

Trombetta, T. B., Oleini, P. H.,, Lopes, B. V., Guimarães, R. C., Marques, W. C., Isoldi L. A. 
incidentes. Embora este efeito também possa ser observado ao norte da instalação, a redução é muito menor. Esta área de sombra em direção ao sul fornece, para futuros estudos, um indicativo que se a orientação da rampa fosse inclinada mais para o norte, talvez o efeito de redução fosse mais eficiente.

\section{Conclusões}

Com os resultados obtidos através das simulações computacionais, foi possível realizar uma análise comparativa entre o cenário natural e o cenário posterior à instalação da rampa. Desse modo, foram identificadas reduções acentuadas na altura significativa e no potencial energético das ondas.

Anteriormente à instalação da rampa, a energia das ondas era dissipada, na maior parte, muito próximo à linha da costa, possibilitando que ondas com maiores alturas atingissem o litoral, causando grandes impactos sobre a zona costeira. Entretanto, após a instalação da rampa, a energia foi dissipada gradualmente ao longo de toda a extensão da estrutura, permitindo que a altura das ondas diminuísse continuamente ao se aproximar da costa, atingindo o litoral com valores energéticos relativamente pequenos. As áreas litorâneas adjacentes à estrutura instalada também demonstraram uma redução significativa do potencial energético das ondas, possibilitando uma maior proteção do ambiente praial na região de interesse. Assim, os resultados obtidos para estes parâmetros foram positivos, uma vez que a dissipação da energia de forma gradual faz com que o impacto sobre a praia seja muito menor que a dissipação súbita de toda a energia da onda.

Outro fator relevante a ser discutido, refere-se ao transporte de sedimentos na região de estudo, que provavelmente sofrerá uma diminuição considerável, visto que a ação das ondas não atuará de maneira tão intensa quanto no cenário natural. Fato este verificado por Silva et al. (2018) que estudaram o comportamento e a influência das ondas em relação ao transporte de sedimentos litorâneos na costa norte da Ilha de Santa Catarina. Dessa forma, será possível que o ambiente costeiro consiga se restabelecer contiguamente, retornando ao equilíbrio natural e evitando processos acrecionais ou erosivos.

Por fim, a instalação da rampa se mostrou uma alternativa válida para a proteção da costa na região do Farol de Santa Marta em Laguna/SC, visto que atenua os efeitos das ondas de forma eficiente. Esta atenuação potencialmente resulta em menores taxas de erosão da praia, refletindo, assim, na diminuição dos valores despendidos anualmente com proteção costeira.

Para estudos futuros, pretende-se modificar as dimensões da rampa, visando definir o modelo mais eficiente para dissipação da energia das ondas, e que não demande grande volume de material para sua construção. Outra proposta está relacionada à realização do cálculo de instalação e construção da estrutura, com objetivo de analisar se a execução da rampa é, de fato, uma alternativa viável economicamente. Assim, é possível definir a estrutura que apresente o maior custo/benefício, priorizando a diminuição da ação erosiva das ondas sobre a região costeira.

\section{Agradecimentos}

Os autores agradecem à Coordenação de Aperfeiçoamento de Pessoal de Nível Superior (CAPES) pela concessão das bolsas de estudo, ao Conselho Nacional de Desenvolvimento Científico e Tecnológico (CNPq) pelo contrato 304227/20161 e ao Centro Nacional de Supercomputação (CESUP), da Universidade Federal do Rio Grande do Sul (UFRGS), que auxiliaram o desenvolvimento deste trabalho. Agradecem também à NOAA pelos dados oceanográficos e meteorológicos utilizados nas condições de contorno do modelo, ao consórcio Open TELEMAC-MASCARET por disponibilizar o sistema TELEMAC gratuitamente e ao Laboratório Nacional de Computação Científica (LNCC) pela disponibilização de uso do Supercomputador Santos Dumont.

\section{Referências}

Airoldi, L., Abbiati, M., Beck, M.W., Hawkins, S.J., Jonsson, P.R., Martin, D., Moschella, P., Sundelof, A., Thompson, R.C. and Aberg, P., 2005. An ecological perspective on the deployment and design of low-crested and other hard coastal defence structures. Coastal Engineering [online] 52. Disponível: https://doi.org/10.1016/j.coastaleng.2005.09.00 7. Acesso: 20 maio 2017.

Bird, E. C. F., 1999. Beach Management, $1^{\text {a }}$ ed. John Wiley \& Sons Inc., New York.

Bonetti, J.; Rudorff, F. M.; Campos, A. V.; Serafim, M. B., 2017. Geoindicator-based assessment of Santa Catarina (Brazil) Sandy beaches susceptibility to erosion. Ocean \& Coastal Management [online] 149. Disponível: https://doi.org/10.1016/j.ocecoaman.2017.08.0 09. Acesso: 25 set. 2017

Bruun, P., 2013. Design and Construction of Mounds for Breakwaters and Coastal 
Protection, 3 ed. Elsevier Science Publishing Company, New York, NY.

Bruun, P., Schwartz, M. L., 1985. Analytical predictions of beach profile change in response to a sea level rise. Zeitschrif $t$ für Gemorphologie N.F., Supplement-Band, 57, 33-50.

Clark, R. R., 1993. Beach conditions in Florida: a statewide inventory and identification of the beach erosion problem areas in Florida (Beaches and Shores Technical and Design Memorandum), $5^{\text {a }}$ ed. Florida Department of Environmental Protection, Florida.

CTTMar. Centro de Ciências Tecnológicas da Terra e do Mar, 1999. Projeto de Recuperação da Praia de Gravatá, Município de Navegantes (SC). Universidade do Vale do Itajaí UNIVALI. Itajaí.

Dias, J. M. A., 1993. Estudo de avaliação da situação ambiental e proposta de medidas de salvaguarda para a faixa costeira portuguesa. Geologia Costeira [online] 1. Disponível: http://w3.ualg.pt/ jdias/JAD/eb_Ambicost.htm 1. Acesso: 20 jul. 2017.

Griggs, G. B.; Trenhaile, A. S., 1994. Coastal cliffs and plataforms, in: R. W. G. Carter e C. D. Wooddroffe (Eds.), Coastal Evolution - Late Quaternary shoreline morphodynamics. Cambridge University Press, Cambridge, pp 450.

Guimarães R. C.; Oleinik, P. H.; Kirinus, E. P.; Lopes, B. V.; Marques, W. C., 2017. An overview of the Brazilian continental shelf wave energy potential. XXXVIII Ibero-Latin American Congress on Computational Methods in Engineering. Florianópolis.

Horn Filho, N.O.; Bonetti Filho, J.; Gré, J.C.R.; Porto Filho, É., 1998. Uma visão geológica e geomorfológica do domínio costeiro da ilha de Santa Catarina. In: Simpósio Nacional De Geomorfologia. Florianópolis, Santa Catarina, Brasil.

Horn Filho, N.O.; Porto Filho, É.; Ferreira, E., 2004. Diagnóstico geológico-geomorfológico da planície costeira adjacente à enseada dos Currais, Santa Catarina, Brasil. In: Simpósio Nacional De Geomorfologia. Florianópolis, Santa Catarina, Brasil. Revista Gravel [online] $2 . \quad$ Disponível: http://www.ufrgs.br/gravel/2/Gravel_2_03.pdf. Acesso: 23 jul. 2017.

IBGE. Instituto Brasileiro de Geografia e Estatística, 2017. Dados gerais do município Laguna. Disponível em: http://cod.ibge.gov.br/6D5. Acesso em: 15 maio 2017.
IPCC, 2014. Climate Change 2014: Synthesis Report, in: Core Writing Team, R. K. Pachauri e L. A. Meyer (Eds.), Contribution of Working Groups I, II and III to the Fifth Assessment Report of the Intergovernmental Panel on Climate Change. IPCC, Geneva, Switzerland, pp. 151.

Klein, A. H. F., 2004. Morphodynamics of headland bay beaches: Examples form the coast of Santa Catarina State, Brazil. Tese (Doutorado). Faro, Universidade do Algarve.

Klein, A. H. F.; Short, A. D.; Bonetti, J., 2016. Santa Catarina Beach Systems, in: Short, A.D., Klein, A.H.F. (Eds.), Brazilian Beach Systems. Springer, Switzerland, pp. 465-506.

Klein, A. H. F.; Menezes, J. T.; Diehl, F. L.; Abreu, J. G. N.; Polette, M.; Sperb, R. M.; Sperb. R. C., 2015. Santa Catarina. In: Dieter Muehe (Org.), Erosão e Progradação do Litoral Brasileiro. Ministério do Meio Ambiente, Brasília, pp. 401-436.

Koerner, K. F.; Oliveira, U. R.; Gonçalves, G., 2013. Efeito de estruturas de contenção à erosão costeira sobre a linha de costa: Balneário Hermenegildo, Rio Grande do Sul, Brasil. Revista da Gestão Costeira Integrada [online] $13 . \quad$ Disponível: http://www.scielo.mec.pt/pdf/rgci/v13n4/v13n 4a05.pdf. Acesso: 18 maio 2017.

Krueger, J., 2011. Análise dos parâmetros meteorológicos e oceanográficos dos eventos de ressaca, ocorridos entre janeiro de 2001 a dezembro de 2010, no Estado de Santa Catarina. Monografia (Graduação). Itajaí, Universidade do Vale do Itajaí.

Lira, A. R., 1997. Caracterização morfológica e vulnerabilidade do litoral entre as praias de Enseadinha e Marinha Farinha - Paulista (PE). Dissertação (Mestrado). Recife, Universidade Federal de Pernambuco.

Lynch, D. R., Ip, J. T. C., Naimie, C. E., Wermer, F. E., 1996. Comprehensive coastal circulation model with application to the Gulf of Maine. Revista Continental Shelf Research [online] 16. Disponível:

http://www.sciencedirect.com/science/article/p ii/0278434395000283. Acesso: 18 maio 2017.

McGuire, B., Mason, I., Kilburn, C., 2002. Natural Hazards and Environmental Change, 1. Routledge, Londres.

MMA. Ministério do Meio Ambiente e da Amazônia Legal, 2000. Agenda 21: Gestão dos Recursos Naturais, Subsídios à elaboração da Agenda 21 Brasileira. Santa Catarina.

Moraes, A. C. R. de, 1995. Os impactos da política urbana sobre a zona costeira. Disponível: 
http://www.mma.gov.br/gestao-

territorial/gerenciamento-

costeiro/publica\%C3\%A7\%C3\%B5es. Acesso: 18 maio 2017.

Muehe, D. (Org.), 2006. Erosão e Progradação do Litoral Brasileiro. Disponível: http://mma.gov.br/estruturas/sqa_sigercom/_pu blicacao/78_publicacao12122008084856.pdf. Acesso: 18 maio 2017.

Muler, M.; Bonetti, J., 2014. An Integrated Approach to Assess Wave Exposure in Coastal Areas for Vulnerability Analysis. Marine Geodesy. [online] 37. Disponível: http://dx.doi.org/10.1080/01490419.2014.9028 86. Acesso em 17 out. 2017.

National Oceanic and Atmospheric Administration, 2016. Historical data from the NOAA WAVE WATCHIII global and regional ocean wave models. Disponível: <ftp://ftp.polar.ncep.noaa.gov/history/waves>. Acesso em 03 maio 2017.

Oleinik P. H., Marques W. C., e Kirinus E. de P., 2017. Estimate of the Wave Climate on the Most Energetic Locations of the SouthSoutheastern Brazilian Shelf. Defect and Diffusion Forum [online] 370. Disponível: https://www.scientific.net/DDF.370.130. Acesso: 15 março 2017.

Paula, D. P. de, 2015. Erosão Costeira e Estruturas de Proteção no Litoral da Região Metropolitana de Fortaleza (Ceará, Brasil): Um contributo para artificialização do litoral. Revista Eletrônica do PRODEMA [online] 9. Disponível: http://www.revistarede.ufc.br/revista/index.ph p/rede/article/viewFile/306/74. Acesso: 17 nov. 2017.

Pianca, C., Mazzini, P.L.F., Siegle, E., 2010. Brazilian Offshore Wave Climate Based on NWW3 Reanalysis. Brazilian Journal of Oceanography [online] 58. Disponível: http://dx.doi.org/10.1590/S167987592010000100006. Acesso: 23 maio 2017.

Polette, M., 1997. Gerenciamento Costeiro Integrado: Proposta metodológica para paisagem litorânea da Microbacia de Mariscal, Município de Bombinhas, (SC), Brasil. Tese (Doutorado). São Carlos, Universidade Federal de São Carlos.

Rohling, E.J.; Grant, K.; Hemleben, C.H.; Siddall, M.; Hoogakker, B.A.A.; Bolshaw, M.; Kucera, M., 2007. High rates of sea level rise during the last interglacial period. Nature Geoscience [online] $1 . \quad$ Disponível: http://dx.doi.org/10.1038/ngeo.2007.28. Acesso: 05 nov. 2017.
Rudorff, F. M., 2005. Geoindicadores e Análise Espacial na Avaliação de Suscetibilidade Costeira a Perigos Associados a Eventos Oceanográficos e Meteorológicos Extremos. Dissertação (Mestrado). Florianópolis, Universidade Federal de Santa Catarina.

Rudorff, F. M.; Bonetti, J., 2010. Avaliação da suscetibilidade à erosão costeira de praias da Ilha de Santa Catarina. Brazilian Journal of Aquatic Science and Technology [online] 14. Disponível:

https://siaiap32.univali.br/seer/index.php/bjast/ article/view/2250/1597. Acesso: 15 nov. 2017.

Scherer, M.; Ferreira, C.; Mudat, J.; Cataneo, S., 2006. Urbanização e gestão do litoral centro-sul do estado de Santa Catarina. Revista Desenvolvimento e Meio Ambiente [online] 13. Disponível:

http://dx.doi.org/10.5380/dma.v13i0.4873.

Acesso: 05 maio 2017.

Silva, I. R.; Bittencourt, A. C. S. P.; Dominguez, J. M. L., 2007. Modelagem de Ondas como Subsídio para a Gestão Ambiental das Praias da Costa do Descobrimento, sul do Estado da Bahia. Anais XIII Simpósio Brasileiro de Sensoriamento Remoto, Florianópolis.

Silva, G. V.; Toldo, E. E.; Klein, A. H. F.; Short, A. D., 2018. The influence of wave, wind and tide-forced currentes on headland sand bypassing - Study case: Santa Catarina Island north shore, Brazil. Geomorphology, v. 312, p. $1-11$.

Solomon, S.; Qin, D.; Manning, M.; Chen, Z.; Marquis, M.; Averyt, K.B.; Tignor, M.; Miller, H. L., 2007. Climate Change 2007: The Physical Science Basis. Intergovernmental Panel on Climate Change [online] 1. Disponível em: $\quad$ http://www.ipcc.ch/ipccreports/ar4wg1.htm. Acesso: 13 ago. 2017.

Souza, C. R. de G., 2001. Coastal erosion risk assessment, shoreline retreat rates and causes of coastal erosion along the state of São Paulo coast, Brazil. Revista Pesquisas em Geociências 28(2), 459- 474.

Souza, C. R. de G., 2004. Projeto SIIGAL: O SIGERCO para o Estado de São Paulo. Revista de Gerenciamento Costeiro Integrado [online] $3 . \quad$ Disponível: http://www.gci.inf.br/edicoes_anteriores/03/09 _sist_inf_geograficas.pdf. Acesso: 01 ago. 2017.

Souza, C. R. de G., 2009. A Erosão Costeira e os Desafios da Gestão Costeira no Brasil. Revista Gestão Costeira Integrada [online] 9. Disponível: http://abes- 
sp.org.br/docs/pdf/celia_erosao_costeira_e_desa fios_gestao_costeira.pdf. Acesso: 15 nov. 2017.

Souza, C. R. de G.; Souza Filho, P. W. M.; Esteves, S. L.; Vital, H.; Dillenburg, S. R.; Patchineelam, S.M.; Addad, J.E., 2005. Praias Arenosas e Erosão Costeira, in: C. R. de G. Souza et al. (Eds.), Quaternário do Brasil. Holos, Ribeirão Preto (SP), pp. 130-152.

TELEMAC-MASCARET Consortium, 2016. Open TELEMAC-MASCARET - The mathematically superior suite of solvers. Disponível: opentelemac.org. Acesso 13 março 2017.

Vallega, A., 2000. Sustainable Ocean Governance: A Geographical Perspective, 1 ed. Routledge, Abingdon - Reino Unido.

Wisner, B., Blaikie, P., Cannon, T., Davis, I., 2004. At Risk: Natural Hazards, Peoples's Vulnerability and Disasters. Routledge, Londres. 